\title{
Estudo anatômico do plexo lombossacral de Tamandua tetradactyla
}

[Anatomical study of the lumbosacral plexus of the Tamandua tetradactyla]

\author{
J.R. Cardoso ${ }^{1}$, P.R. Souza ${ }^{1}$, V.S. Cruz ${ }^{1}$, E.J. Benetti ${ }^{1}$, M.S. Brito e Silva ${ }^{1}$, P.C. Moreira ${ }^{1}$, \\ A.A.L. Cardoso ${ }^{2}$, A.K. Martins ${ }^{2}$, T. Abreu ${ }^{3}$, K. Simões ${ }^{1}$, F.R. Guimarães ${ }^{4}$ \\ ${ }^{1}$ Instituto de Ciências Biológicas - Universidade Federal de Goiás - Goiânia, GO \\ ${ }^{2}$ Médicos autônomos - Uberlândia, MG \\ ${ }^{3}$ Bióloga autônoma - Goiânia, GO \\ ${ }^{4}$ FAMEVZ - Universidade Federal de Mato Grosso - Cuiabá, MT
}

\begin{abstract}
RESUMO
O tamanduá-mirim (Tamandua tetradactyla) é um xenartro da família Myrmecophagidae, encontrado da Venezuela ao sul do Brasil. Estudos apontam que essa é uma das espécies de animais selvagens mais vitimadas em número de atropelamentos, e, muitas vezes, o atendimento clínico adequado aos indivíduos feridos é dificultado pela carência de informações acerca dos mesmos. Visando contribuir com o conhecimento dessa espécie, este estudo teve como objetivo descrever seu plexo lombossacral. Para tanto, foram utilizados quatro cadáveres de Tamandua tetradactyla adultos e de ambos os sexos. O plexo lombossacral dessa espécie é formado pelos ramos ventrais dos nervos espinhais T18, L1, L2, L3, S1, S2, S3, S4, S5. Os nervos integrantes do plexo lombossacral do $T$. tetradactyla com suas formações mais frequentes foram os seguintes: genitofemoral (T18), cutâneo femoral lateral (T18-L1), femoral (T18, L1-L3), obturador (T18, L1-L3), glúteo cranial (L3-S1), isquiático (L3-S3), pudendo (S3-S4 ou S4-S5), retal caudal (S4 ou S5) e cutâneo femoral caudal (S4-S5). O plexo lombar e sacral dessa espécie é unido, sendo L3 o ponto de união entre eles. Devido ao pequeno número de vértebras lombares, a composição dos nervos do plexo lombossacral do T. tetradactyla apresenta características peculiares que se diferem das características das demais espécies já estudadas, quais sejam, a ausência dos nervos ílio-hipogástrico e ilioinguinal e participação de nervos torácicos na composição dos nervos do plexo lombar, presença de contribuição sacral na composição do nervo obturador e ausência de contribuição lombar na composição do nervo isquiático e um limite mais caudal na extensão do plexo sacral.
\end{abstract}

Palavras-chave: tamanduá-mirim; sistema nervoso; inervação do membro pélvico, Xenarthra

\begin{abstract}
The lesser anteater (Tamandua tetradactyla) is a xenarthra of the Myrmecophagidae family found from Venezuela to southern Brazil. Studies have shown that this is one of the most numerous wildlife species victims of car collisions on roads, and often the appropriate clinical care to injured animals is hindered by the lack of information about them. In order to contribute to the knowledge of this species, this study aimed to describe its lumbosacral plexus. For this purpose, four cadavers of adult specimens of both sexes of $\mathrm{T}$. tetradactyla were used. The lumbosacral plexus of the T. tetradactyla is formed by the ventral rami of spinal nerves T18, L1, L2, L3, S1, S2, S3, S4, S5. The lumbosacral plexus nerves with their most common formations in this species were as follows: genitofemoral (T18), lateral femoral cutaneous (T18-L1), femoral (T18, L1-L3), obturator (T18, L1-L3), cranial gluteal (L3-S1), ischiatic (L3-S3), pudendus (S3-S4 or S4-S5), caudal retal (S4 or S5), and caudal femoral cutaneous (S4-S5). The lumbar and sacral plexus of this species is joined, L3 being the link between them. Due to the small number of lumbar vertebrae, the arrangement of the lumbosacral plexus nerves of the T. tetradactyla showed peculiar characteristics that differ it from that of other previously studied species, such as the absence of iliohypogastric and ilioinguinal nerves and contribution of thoracic nerves in the formation of all the nerves of the lumbar plexus, presence of sacral contribution in the formation of the obturator nerve, and the lack of lumbar contribution for sciatic nerve formation and a most caudal extent of the sacral plexus.
\end{abstract}

Keywords: lesser anteater; nervous system; pelvic limb innervation, Xenarthra

Recebido em 2 de julho de 2012

Aceito em 13 de junho de 2013

E-mail: juliorcardoso@gmail.com 


\section{INTRODUÇÃO}

Os indivíduos da ordem Xenarthra parecem ter se originado na América do Sul, onde atualmente são divididos em quatro famílias que abrangem os tamanduás, os tatus e as preguiças. Os tamanduás constituem uma só família (Myrmecophagidae) com características anatomofisiológicas e comportamentais similares (Miranda e Costa, 2006), representada por três gêneros: Myrmecophaga (tamanduá-bandeira), Tamandua (tamanduá-mirim) e Cyclopes (pigmeu) (Diniz et al., 1995). O Tamandua tetradactyla é conhecido popularmente como tamanduá-mirim ou tamanduá-de-colete, devido aos pelos pretos que cruzam os ombros em faixa e cobrem o dorso e o ventre, formando um desenho similar a um colete preto (Nowak, 1999).

Essa espécie se distribui ao leste dos Andes, do sul da Venezuela ao norte da Argentina e Uruguai (Miranda e Costa, 2006), sendo encontrada em todo o território brasileiro (Cardinot et al., 2007). Tem hábitos arborícolas, embora também se movimente no solo (Rodrigues et al., 2009). De hábito noturno/crepuscular (Miranda e Costa, 2006), é solitário e alimenta-se basicamente de cupins de chão e árvores, formigas, abelhas e mel (Rodrigues et al., 2009).

A constituição do plexo lombossacral dos animais domésticos é bem estabelecida nos tratados de anatomia animal, sendo composta pelos ramos ventrais de L2-L6-S1 em equinos, bovinos e suínos (Getty, 1986; Frandson et al., 2011), podendo ter participação de L1 em equinos (Getty, 1986) e por L3-L7 e S1-S3 em cães (Miller, 1964). Todavia, foram poucos os estudos da formação desse plexo nos demais mamíferos não primatas.

O conhecimento da formação desse plexo, além de contribuir para o estudo da anatomia comparada, pode oferecer dados que colaborem diretamente para a realização bem-sucedida de condutas clínicas, cirúrgicas e anestésicas nessa espécie. Nesse sentido, o objetivo deste estudo foi descrever a anatomia do plexo lombossacral no Tamandua tetradactyla, no que se refere à sua origem, composição e nervos resultantes.

\section{MATERIAL E MÉTODOS}

Foram utilizados quatro exemplares adultos de tamanduá-mirim (Tamandua tetradactyla), sendo duas fêmeas, um macho e outro indivíduo sem identificação, por ter tido seus órgãos genitais removidos em necropsia. Os animais foram doados pelo Instituto Brasileiro do Meio Ambiente e dos Recursos Naturais Renováveis (IBAMA-GO); portanto, nenhum animal foi eutanasiado especificamente para este trabalho, que foi previamente aprovado pela comissão de ética no uso de animais (Processo CEUA-UFG $\mathbf{n}^{\circ}$ 021/11). Ao dar entrada no Laboratório de Anatomia Animal do Instituto de Ciências Biológicas (ICB) da UFG, os cadáveres foram descongelados, higienizados com água corrente, fixados por meio de injeções com solução de formol a $10 \%$ e conservados na mesma solução. $\mathrm{O}$ acesso à cavidade abdominal e pélvica se deu a partir de uma incisão longitudinal na linha alba e remoção de parte dos púbis e sínfise pélvica. Para a visualização dos ramos ventrais dos nervos espinhais que originam o plexo lombossacral, suas comunicações e os nervos originados desse plexo, foram afastados o cólon e reto, os órgãos genitourinários e os vasos sanguíneos lombares e sacrais, e removidos o peritônio parietal, fáscias pélvicas e parte da musculatura sublombar. As estruturas nervosas desejadas foram dissecadas e os achados foram mapeados e fotografados, sendo a nomenclatura empregada para a descrição dos resultados a do International ... (2012).

\section{RESULTADOS E DISCUSSÃO}

Até onde se pode constatar, não há, até o presente momento, descrições da formação do plexo lombossacral em outros membros da ordem Pilosa, ou mesmo da superordem Xenarthra. Portanto, os resultados deste estudo foram discutidos com relatos em outras espécies de animais selvagens e com descrições em animais domésticos relatadas em livros-textos da área morfológica.

É imprescindível em estudos desta natureza realizar a contagem cuidadosa do número de vértebras dos segmentos da coluna vertebral relacionados com a origem dos ramos nervosos de cada exemplar. Já fora relatada a presença de seis vértebras lombares em $T$. tetradactyla (Machado e Santos, 2008); todavia, neste estudo, 
foram observadas 18 vértebras torácicas, três lombares e cinco sacrais, coincidindo com os relatos de Flower (1885) e Sánchez-Villagra et al. (2007).

Para se considerar o plexo lombar e sacral unidos, constituindo um plexo lombossacral, é necessário que haja um elo entre eles, que é representado por um ramo lombar que contribua com a composição de nervos pertencentes aos dois plexos (Barros et al., 2003). Em três exemplares do presente estudo (75\%), o plexo lombar e sacral encontraram-se unidos, constituindo de fato um plexo lombossacral, sendo o último segmento lombar (L3) o elo entre eles; pois, sendo bifurcado, esse ramo contribuiu tanto com a formação de nervos do plexo lombar quanto do sacral (Fig. 1 e 2). Em um exemplar $(25 \%)$, entretanto, não houve comunicação entre L3 e os ramos sacrais para formação do plexo sacral (Fig. 3).

O plexo lombossacral do $T$. tetradactyla foi formado pelos ramos ventrais de nove segmentos medulares, sendo eles T18, L1, L2, L3, S1, S2, S3, S4 e S5. Em um exemplar, houve uma migração caudal do plexo e não seu alongamento, sendo este formado por L1, L2, L3, S1, S2, S3, S4, S5, Coc1. Esse caso representa, portanto, um plexo lombossacral pósfixado, que constitui uma variação comum observada em primatas (El-Assy, 1965; Barros et al., 2003).

Estabelecer a comparação do limite cranial e caudal da formação do plexo lombossacral com os dados publicados sobre os plexos de outras espécies tem como fatores complicadores as variações anatômicas, a diferença do número de vértebras da coluna lombar e sacral entre as espécies - ou mesmo dentro da mesma espécie -, mas, principalmente, a falta de consenso de quais nervos compõem esse plexo. No que se refere ao limite cranial do plexo lombossacral, alguns autores incluem os primeiros nervos lombares como integrantes do mesmo, ou seja, os nervos ílio-hipogástrico (cranial e caudal, quando presentes) e ilioinguinal e genitofemoral (Getty, 1986; Aydin, 2009; Castro et al., 2009). Todavia, essa abordagem extrapola o conceito de que somente os nervos lombares caudais estabelecem comunicações para configurar um plexo nervoso, uma vez que os primeiros nervos lombares são formados por ramos solitários (König e Leibich, 2002; Dyce et al., 2010).

O limite caudal do plexo lombossacral também é controvertido. $\mathrm{O}$ nervo pudendo foi abordado no estudo desse plexo por Lacerda et al. (2006), Aydin (2009), Castro et al. (2009), MartinezPereira e Rickes (2011), e o retal caudal pelos mesmos autores, exceto Larcerda et al. (2006). Quanto aos tratados de anatomia animal, König e Liebich (2002) incluem esses dois nervos no plexo sacral, mas Getty (1986) e Dyce et al. (2010) os descrevem separadamente como nervos sacrais. Para Schaller (1999), o plexo sacral é constituído pelos nervos responsáveis pela inervação dos músculos caudais da coxa e de toda a perna e pé, além da pele correspondente, o que restringe, portanto, a abordagem aos nervos glúteos cranial e caudal, cutâneo femoral caudal e isquiático. Todos os nervos em questão estiveram presentes no $T$. tetradactyla e, portanto, foram abordados no presente estudo.

Apesar de a maior parte dos tamanduás deste estudo $(75 \%)$ apresentar de fato um plexo lombossacral, a descrição dos dois plexos será realizada separadamente para melhor apresentação dos resultados.

O plexo lombar recebeu contribuição de T18-L3 em três casos e L1 a S1 em um caso. Esse plexo é constituído pelos nervos responsáveis pela inervação dos músculos craniais e mediais da coxa e a pele do aspecto medial da coxa, perna, tarso e metatarso (Schaller, 1999), o que inclui os nervos genitofemoral, cutâneo femoral lateral, femoral e obturador. Por apresentar somente três vértebras lombares, o $T$. tetradactyla não apresenta os nervos ílio-hipogástrico e ilioinguinal, sendo o nervo genitofemoral o mais cranial dos nervos lombares nos exemplares deste estudo. O território de inervação dos referidos nervos ausentes nessa espécie foi suprido pelo nervo costoabdominal, que corresponde ao ramo ventral do último nervo torácico (Schaller, 1999), mas no T. tetradactyla ele recebe fibras também de T17. Curiosamente, esse é o comportamento padrão dos nervos intercostais dessa espécie, ou seja, os ramos ventrais torácicos são bifurcados, de forma que cada nervo intercostal é formado tanto por fibras de seu segmento medular correspondente quanto do seu segmento cranial (Fig. 1). Até onde 
pudemos constatar, não há relato desse comportamento em outras espécies.

Participaram da constituição do plexo lombar do $T$. tetradactyla os ramos ventrais dos nervos espinhais T18, L1, L2 e L3, não havendo diferença nessa formação entre os antímeros.

O nervo genitofemoral (Fig. 1, 2 e 3) derivou de T18 em dois casos (50\%), de T18 e L1 em um caso (25\%) e L1 e L2 também em um caso (25\%). A participação de nervos torácicos na formação dos nervos do plexo lombar, como observado em $75 \%$ dos exemplares deste estudo e em porcos-espinhos (Aydin, 2009), é incomum. Essa diferença se deve provavelmente à menor quantidade de vértebras lombares nessas espécies, sendo três no $T$. tetradactyla e quatro no Hystrix cristata. A formação do nervo genitofemoral do $T$. tetradactyla difere-se da descrita em animais domésticos, sendo formado nestes últimos exclusivamente por ramos lombares, sendo L3 e L4, podendo ter participação de L2 (Miller, 1964; Getty, 1986; Schaller, 1999).

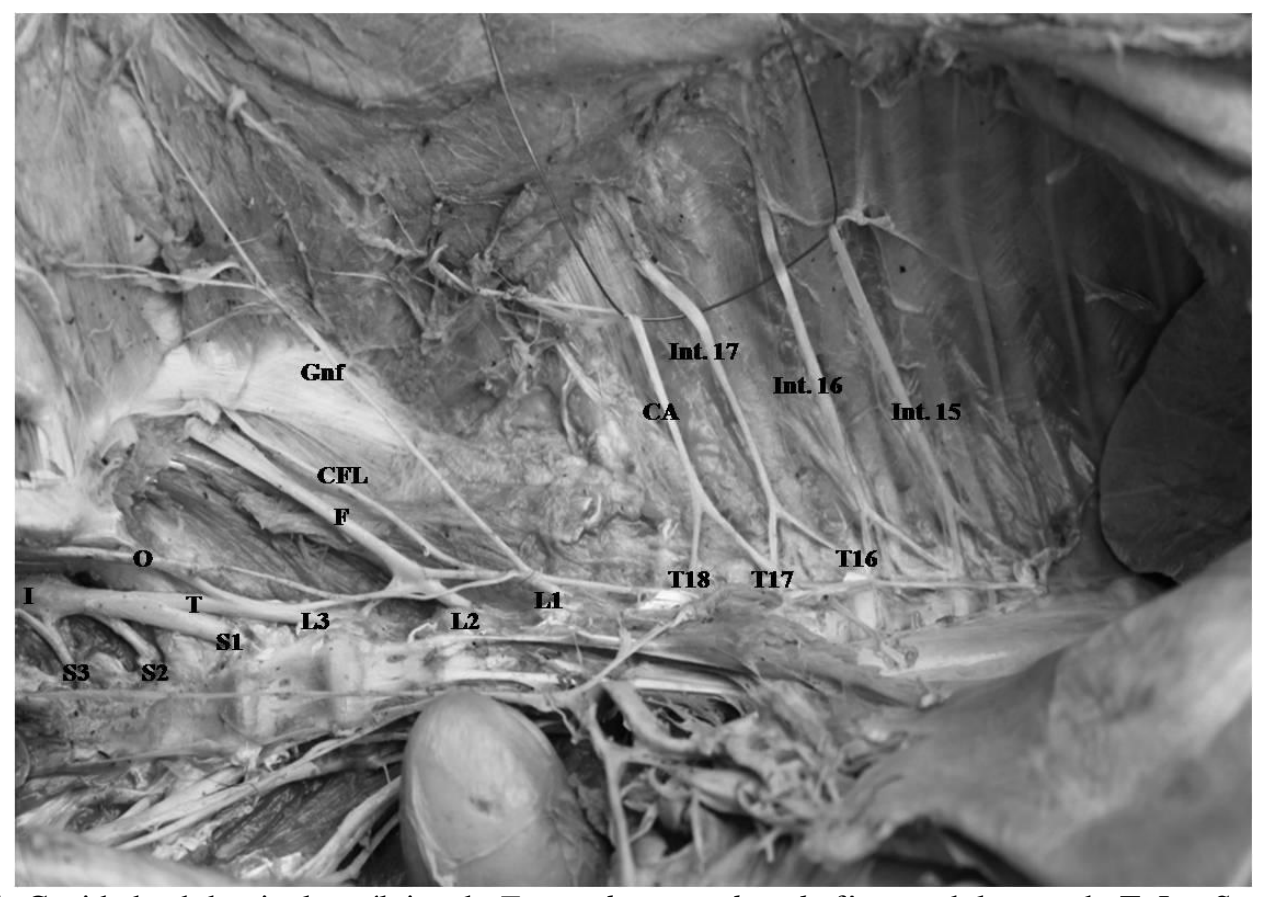

Figura 1. Cavidade abdominal e pélvica de Tamandua tetradactyla fêmea adulta, sendo T, L e S os ramos ventrais dos nervos torácicos, lombares e sacrais, respectivamente; Int., nervos intercostais; CA, n. costoabdominal; Gnf, n. genitofemoral; CFL, n. cutâneo femoral lateral; F, n. femoral; O, n. obturador; T, tronco lombossacral; I, n. isquiático.

O nervo cutâneo femoral lateral (Fig. 1, 2 e 3) do T. tetradactyla foi formado por T18-L1 em três casos $(75 \%)$ e L1-L2 em um caso (25\%). Ele é formado por L3-L4(L5) nos animais domésticos (Getty, 1986; Schaller, 1999), T15-L1 no porcoespinho (Aydin, 2009), L3 no lobo-marinho (Castro et al., 2009) e L4 em chinchilas (Martinez-Pereira e Rickes, 2011).

O nervo femoral (Fig. 1, 2 e 3) foi o mais calibroso do plexo lombar, o que corrobora a descrição de Schaller (1999), referindo-se aos animais domésticos. Ele recebeu contribuição de todos os ramos lombares (L1-L3) em todos os exemplares deste estudo, e ainda a participação de T18 em 75\% deles. Essa formação assemelhase à do porco-espinho (T15, L1-L3) (Aydin, 2009), mas diferencia-se substancialmente dos animais com maior número de segmentos lombares, sendo formado por L3 a L6 no equino, suíno e em parte dos cães (Getty, 1986), L4-L6 em bovinos (Getty, 1986) e mocós (Lacerda et al., 2006), L3 e L4 no lobo-marinho (Castro et al., 2009) e L4 e L5 em chinchila (MartinezPereira e Rickes, 2011). 


\section{Cardoso et al.}

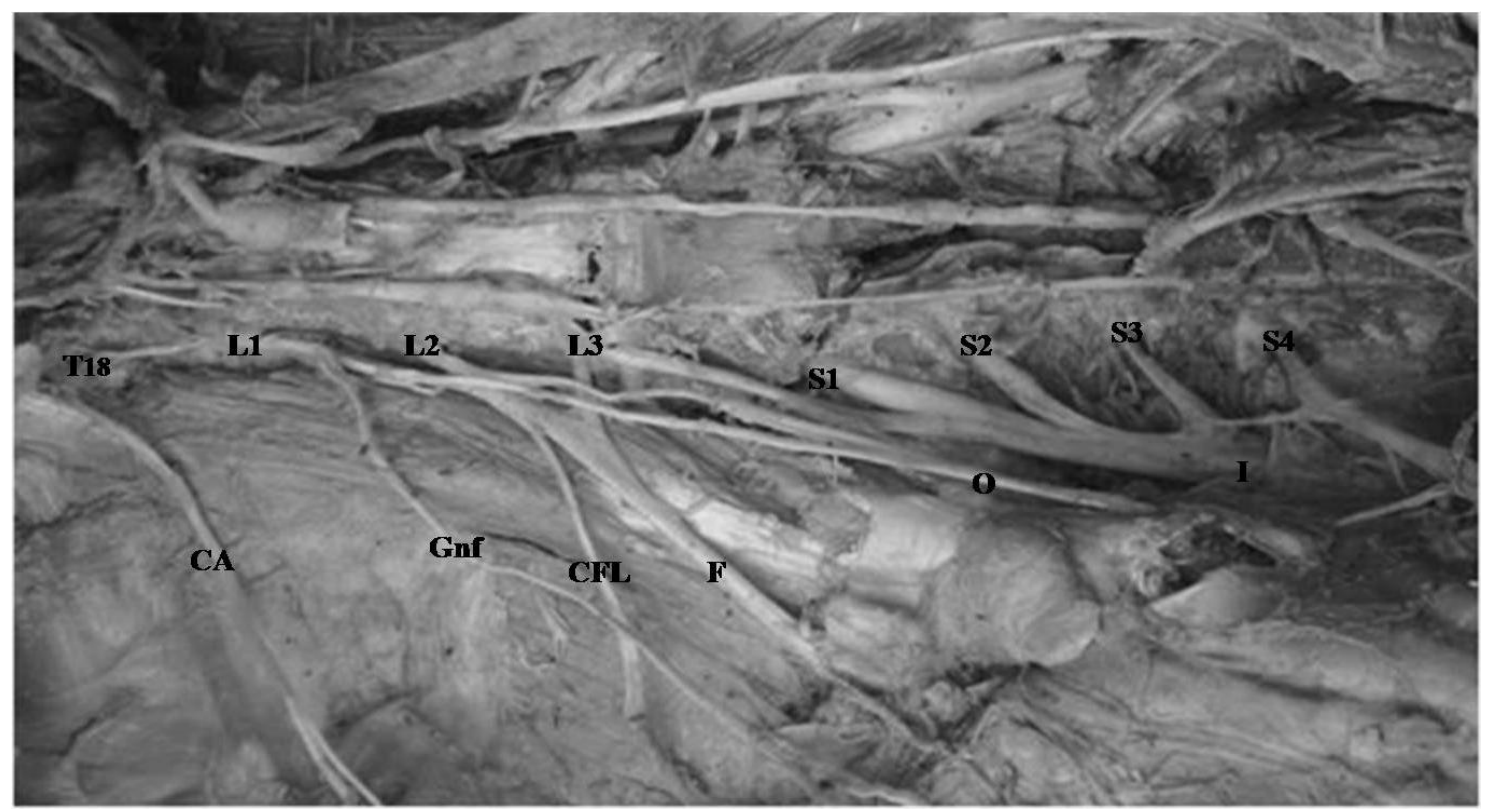

Figura 2. Cavidade abdominal e pélvica de Tamandua tetradactyla macho adulto, sendo T, L e $\mathrm{S}$ os ramos ventrais dos nervos torácicos, lombares e sacrais, respectivamente; CA, n. costoabdominal; Gnf, $n$. genitofemoral; CFL, n. cutâneo femoral lateral; F, n. femoral; O, n. obturador; I, n. isquiático.

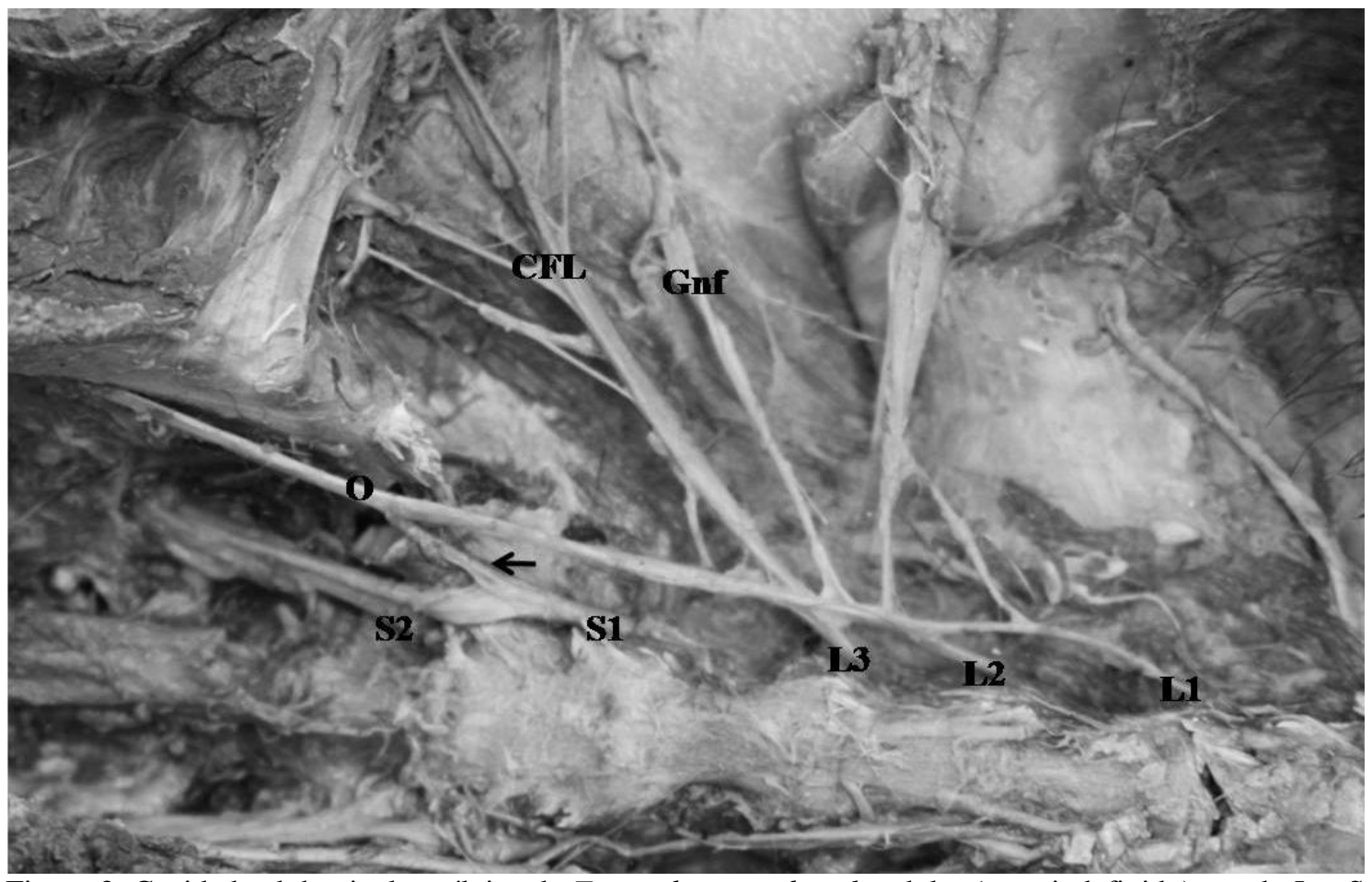

Figura 3. Cavidade abdominal e pélvica de Tamandua tetradactyla adulto (sexo indefinido), sendo L e S os ramos ventrais dos nervos lombares e sacrais, respectivamente; Gnf, n. genitofemoral; CFL, n. cutâneo femoral lateral; O, n. obturador. Notar a contribuição de S1 para a formação do nervo obturador (seta) e a ausência de ramos lombares para a formação do plexo sacral. 
O nervo obturador (Fig. 1, 2 e 3 ) é o nervo mais caudal do plexo lombar e foi formado por T18L3 em 75\% dos casos e L1-S1 em um caso (25\%). Ele teve, portanto, a mesma constituição do N. femoral na maioria dos exemplares de $T$. tetradactyla, o que também ocorre em equinos e suínos (Getty, 1986), porco-espinho (Aydin, 2009), humanos (Moore e Dalley, 2006) e chinchilas (Martinez-Pereira e Rickes, 2011). Mas, em algumas espécies, há uma tendência de o nervo obturador receber uma raiz adicional do segmento medular caudal em relação ao nervo femoral, como em cães (Miller, 1964), caprinos e ovinos (Getty, 1986). Um fato notório neste estudo foi a presença de contribuição de segmento sacral (S1) na formação do nervo obturador de um exemplar (Fig. 3), sendo esse o primeiro relato dessa evidenciação.

O plexo sacral (Fig. 4) do T. tetradactyla recebeu contribuições de L3 a S5 em dois_casos (50\%), de L2 a S5 ou S1 a Coc1 em um caso cada $(25 \%)$.

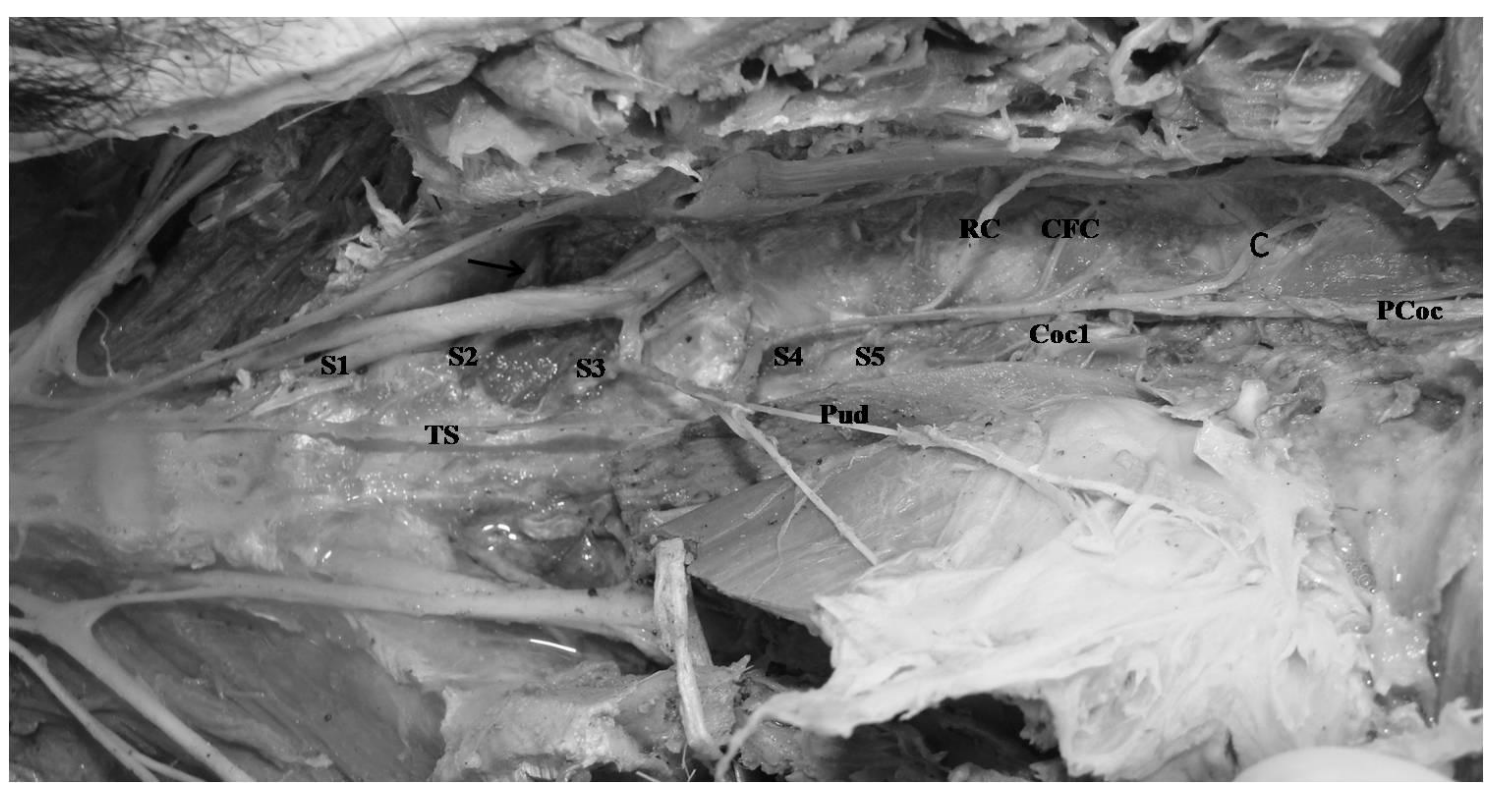

Figura 4. Cavidade pélvica de Tamandua tetradactyla fêmea, adulta, sendo S e Coc os ramos ventrais dos nervos sacrais e coccígeo, respectivamente; seta, n. glúteo cranial; I, n. isquiático; RC, n. retal caudal; Pud, nervo pudendo; CFC, n. cutâneo femoral caudal; C, n. caudal; TS, tronco simpático; PCoc, plexo coccígeo.

No lobo-marinho (Castro et al., 2009) e na chinchila (Martinez-Pereira e Rickes, 2011), a confluência dos segmentos dos dois últimos segmentos lombares e do primeiro sacral forma um tronco nervoso, o plexo isquiático, que emite os nervos glúteos cranial e caudal, cutâneo femoral caudal e isquiático. Esse tronco no tamanduá origina o nervo glúteo cranial e continua como nervo isquiático. $\mathrm{O}$ nervo cutâneo femoral caudal teve origem separada em $100 \%$ dos exemplares, e o nervo glúteo caudal derivou desse tronco somente no antímero direito de um exemplar.

O tronco lombossacral é outro componente do plexo sacral (Schaller, 1999), e sua conceituação e, logo, sua formação, é outro aspecto que suscita controvérsia na abordagem desse tema. Segundo Miller (1964), o tronco lombossacral é a maior e mais importante parte do plexo lombossacral, uma vez que ele continua para fora da pelve como nervo isquiático, sendo formado no cão por L6, L7, S1 e eventualmente S2. Esse conceito, em que há a contribuição de ramos sacrais na composição desse tronco nervoso, é suportado por Getty (1986) e Dyce et al. (2010), que citam que o tronco lombossacral é formado de forma geral pelos três últimos nervos lombares e os dois primeiros sacrais. Por outro lado, Schaller (1999) cita que o tronco lombossacral é representado pelo ramo oriundo do plexo lombar que reforça o plexo sacral, ou seja, o autor não considera, portanto, a participação de raízes sacrais na sua formação, o que difere do descrito 
em humanos, em que esse tronco é constituído somente pelos dois últimos ramos lombares (L4 e L5) (Dangelo e Fattini, 2002; Moore e Dalley, 2006). A contribuição lombar para a constituição dos nervos do plexo sacral esteve presente em três dos quatro exemplares de T. tetradactyla, sendo representada por L2 e L3 em um caso, e por L3 em dois casos. Adotando o conceito de Schaller (1999), somente um exemplar (25\%) apresentou o tronco lombossacral (Fig. 1), haja vista o fato de que L3, por si só, não pode ser considerado um tronco nervoso. Os autores Aydin (2009), Castro et al. (2009), MartinezPereira e Rickes (2011) não se referiram ao tronco lombossacral em seus estudos.

O nervo isquiático (Fig. 1, 2 e 4) do $T$. tetradactyla derivou de L3 a S3 em dois exemplares (50\%), com a participação de L2 em um exemplar (25\%). Em um exemplar, a participação de ramos lombares foi substituída por uma raiz sacral adicional, sendo formado por S1 a S4. A ausência de ramos lombares na sua formação (Fig. 3) não fora reportada em outra espécie, e, além do mais, há um deslocamento caudal na composição do nervo isquiático no $T$. tetradactyla. A contribuição de S3 é reportada somente em humanos (Dangelo e Fattini, 2002; Moore e Dalley, 2006), e não há relatos da participação de S4. Isso talvez se deva ao menor número de vértebras lombares em relação às sacrais nos tamanduás. O nervo isquiático é formado por L6, S1 e S2 em ruminantes (Getty, 1986) e chinchilas (Martinez-Pereira e Rickes, 2011), e pelos dois últimos nervos lombares e os dois primeiros sacrais no cão, gato e equino (Getty, 1986),_no mocó (Lacerda et al., 2006) e no porco-espinho (Aydin, 2009).

O nervo glúteo cranial (Fig. 4) do T. tetradactyla deixa dorsalmente o tronco do plexo sacral antes de este receber S3 para continuar como nervo isquiático. Ele recebeu contribuição de L2 e L3 ou S1 e S2 em um exemplar cada (25\%) e L3 e $\mathrm{S} 1 \mathrm{em}$ dois exemplares $(50 \%)$. O nervo glúteo cranial é formado por L7 no mocó (Lacerda et al., 2006), L3 ou L3-L4 no porco-espinho (Aydin, 2009), pelos dois últimos segmentos lombares e S1 nos cães (Getty, 1986) e lobosmarinhos (Castro et al., 2009) e por L5, L6 e S1 no equino (Getty, 1986) e na chinchila (Martinez-Pereira e Rickes, 2011).
O nervo glúteo caudal derivou diretamente do plexo sacral em um antímero de um único exemplar. $\mathrm{O}$ fato de esse nervo não ter derivado diretamente do plexo sacral no $T$. tetradactyla coincide com as descrições de Getty (1986) em ruminantes e Barros et al. (2003) no macaco Cebus apella. Porém, em espécies como lobosmarinhos (Castro et al., 2009) e mocós (Lacerda et al., 2006), ele originou-se diretamente do plexo sacral, tendo em ambos os casos a mesma constituição do N. glúteo cranial, como observado no nosso exemplar.

O nervo pudendo (Fig. 4) do T. tetradactyla derivou de S3-S4 ou S4-S5 em dois exemplares cada. Esses ramos reúnem-se num tronco comum, do qual parte, cranialmente em direção ao plexo pélvico, o nervo pélvico, e, caudalmente, o nervo pudendo. $\mathrm{O}$ nervo pudendo apresenta uma grande variação na sua formação, mas, de forma geral, ela é mais caudal no $T$. tetradactyla do que nos demais animais de menor porte. Ele é formado por S2 no porcoespinho (Aydin, 2009), mais frequentemente por S2-S3 em suínos, carnívoros domésticos (Getty, 1986; Schaller, 1999), mocó (Lacerda et al., 2006) e lobo-marinho (Castro et al., 2009) e por $\mathrm{S} 3$, podendo ter participação de S2 e S4 em ruminantes e equinos (Getty, 1986; Schaller, 1999), animais estes, cuja formação se aproxima mais à observada no tamanduá.

O nervo retal caudal (Fig. 4) do T. tetradactyla foi formado por S4 ou S5 em dois exemplares cada. Esse padrão de formação monossegmentar também é reportado em equinos, bovinos e suínos (Getty, 1986), sendo S4 o segmento envolvido, e no porco-espinho (S2) (Aydin, 2009), diferente do observado em cães (Getty, 1986), lobo-marinho (Castro et al., 2009) e chinchila (Martinez-Pereira e Rickes, 2011), cuja formação deriva de dois segmentos medulares, S2 e S3. Em cães, o nervo retal caudal pode ainda ser ramo do nervo pudendo (Miller, 1964; Schaller, 1999; Evans e deLahunta, 2000).

O nervo cutâneo femoral caudal (Fig. 4) do $T$. tetradactyla foi formado por $\mathrm{S} 4-\mathrm{S} 5 \mathrm{em}$ dois exemplares, S5 ou S5-Coc1 em um exemplar cada. A identificação desse nervo demanda uma criteriosa análise de sua distribuição, pois o mesmo é delgado, de difícil acesso para dissecação, e apresenta origem bastante variada entre espécies. Ele deriva da borda ventral do 
nervo glúteo caudal de equinos ou da borda dorsal do nervo isquiático de ruminantes, enquanto, em suínos, deriva de S2-S3, podendo receber contribuição de S1 (Getty, 1986). No lobo-marinho (Castro et al., 2009) e na chinchila (Martinez-Pereira e Rickes, 2011), ele provém do mesmo tronco nervoso do plexo isquiático, que emite os nervos glúteo cranial e glúteo caudal e isquiático. Não há, entretanto, relato da participação de nervos coccígeos na formação do mesmo, como observado no presente estudo.

\section{CONCLUSÕES}

O plexo lombar e sacral do T. tetradactyla é unido, sendo L3 o ponto de união entre eles. Devido ao pequeno número de vértebras lombares, a composição dos nervos do plexo lombossacral do $T$. tetradactyla apresenta características peculiares que diferem das outras espécies estudadas, quais sejam, a ausência dos nervos ílio-hipogástrico e ilioinguinal, participação de nervos torácicos na composição de todos os nervos do plexo lombar, presença de contribuição sacral na composição do nervo obturador e ausência de contribuição lombar na composição do nervo isquiático e um limite mais caudal na extensão do plexo sacral, podendo alcançar S4.

\section{AGRADECIMENTOS}

Ao IBAMA-GO, por ter fornecido os animais deste estudo.

\section{REFERÊNCIAS}

AYDIN, A. The dissemination of the pelvic limb nerves originating from the lumbosacral plexus in the porcupine (Hystrix cristata). Vet. Med., v.54, p.333-339, 2009.

BARROS, R.A.C.; PRADA, I.L.S.; SILVA, Z. et al. Constituição do plexo lombar em macaco Cebus apella. Braz. J. Vet. Res. Anim. Sci., v.40, p.373-381, 2003.

CARDINOT, C.B.; FERREIRA, F.S.; PONTES, L.A.E. et al. Avaliação Eletrocardiográfica de Tamanduá-Mirim (Tamandua tetradactyla) no Período Pós Trauma - Relato de Caso. Rev. Univ. Rural, Ser. Ci. Vida, v.27, p.60-62, 2007.
CASTRO, T.F.; SOUZA, D.A.S.; SILVA FILHO, R.P. et al. Sistematização e distribuição da inervação lombar e sacral em Arctocephalus Australis. Braz. J. Vet. Res. Anim. Sci., v.46, p.404-411, 2009.

DANGELO, J.G.; FATTINI, C.A. Anatomia básica dos sistemas orgânicos. 2.ed. São Paulo: Atheneu, 2002. 184p.

DINIZ, L.S.M; COSTA, E.O.; OLIVEIRA, P.M.A. Clinical disorders observed in anteaters (Myrmecophagidae, Edentata) in captivity. Vet. Res. Commun., v.19, p.409-415, 1995.

DYCE, K.M.; SACK, W.O; WENSING, C.J.G. Tratado de anatomia veterinária, 4.ed. Rio de Janeiro: Elsevier, 2010. 834p.

EL-ASSY, Y.S. Beiträge zur morphologie des peripheren nervensystems der primate. Gegenbaur Morph. Jahrb., v.108, p.476-567, 1966.

EVANS, H.E.; deLAHUNTA, A. Guia para a dissecção do cão. 5.ed. Rio de Janeiro: Guanabara Koogan, 2001. 250p.

FLOWER, W.H. An introduction to the osteology of the mammalian. 3.ed. London: Macmillan and Co., 1885. 382p.

FRANDSON, R.D; WILKE, W.L.; FAILS, A.D. Anatomia e fisiologia dos animais de fazenda. 7.ed. Rio de Janeiro: Guanabara Koogan, 2011. 413p.

GETTY, R. Anatomia dos animais domésticos. 5.ed. Rio de Janeiro: Guanabara Koogan, 1986. 2000p.

INTERNATIONAL Committee On Veterinary Gross Anatomical Nomenclature. Nomina Anatomica Veterinaria. 5.ed. Ithaca: Cornell University, 2012. 160p.

KÖNIG, H.E.; LIEBICH, H.J. Anatomia dos animais domésticos. Porto Alegre: Artmed, 2002. 399p.

LACERDA, P.M.O; MOURA, C.E.B.; MIGLINO, M.A. et al. Origem do plexo lombossacral de mocó (Kerondo rupestris). Braz. J. Vet. Res. Anim. Sci., v.43, p.620-628, 2006. 
MACHADO, G.V.; SANTOS, B.S. Topografia do cone medular no tamanduá-mirim (Tamandua tetradactyla Linnaeus, 1758) (Xenarthra: Myrmecophagidae). Arch. Vet. Sci., v.13, p.172175, 2008.

MARTINEZ-PEREIRA，M.A.; RICKES，E.M The spinal nerves that constitute the lumbosacral plexus and their distribution in the chinchilla. $J$. S. Afr. Vet. Assoc., v.82, p.150-154, 2011.

MILLER, M.E. Anatomy of the dog. Philadelphia: W. B. Saunders, 1964. 941p.

MIRANDA, F.; COSTA, A.M. Xenarthra (tamanduá, tatu, preguiça). In: CUBAS, Z.S.; SILVA, J.C.R.; CATÃO-DIAS, J.L. Tratado de animais selvagens. São Paulo: Roca, 2006. p.402- 414 .

MOORE, K.L.; DALLEY, A.T. Anatomia orientada para a clínica. 5.ed. Rio de Janeiro: Guanabara Koogan, 2006. 1101p.
NOWAK, R.M. Walker's mammals of the world. 6.ed., Baltimore and London: The John Hopkins University Press, 1999. 836p.

RODRIGUES, M.C.; QUESSADA, A.M.; DANTAS, D.A.S.B. et al. Amputação do Membro Pélvico Esquerdo de Tamanduá-Mirim (Tamandua tetradactyla): Relato de Caso. Cienc. Anim. Bras., v.10, p.330-334, 2009.

SÁNCHEZ-VILLAGRA， M.R.; NARITA, Y.; KURATANI, S. Thoracolumbar Vertebral Number: First Skeletal Synapomorphy For Afroterian Mammals. Syst. Biodivers., v.5, p.1-7, 2007.

SCHALLER, O. Nomenclatura anatômica veterinária ilustrada. 1.ed. São Paulo: Manole, 1999. 494p. 